\title{
OS AMERÍNDIOS NAS REDES DO SOBRENATURAL CRISTÃO
}

\author{
GLÓRIA KOK ${ }^{1}$
}

UNICAMP

\begin{abstract}
RESUMO: Este artigo investiga a atuação dos jesuitas na reorganização do mundo dos mortos dos Tupi-Guarani, de modo a inseri-lo no modelo sobrenatural cristão. Em conseqüência, imagens e visões associadas ao Céu, Inferno e Purgatório foram difundidas e traduzidas, de formas múltiplas, pelos índios da América portuguesa durante o processo de catequização.
\end{abstract}

PALAVRAS-CHAVE: Índios do Brasil; Jesuitas; Catequese; História do Brasil.

ABSTRACT: This article examines the work of Jesuits on the reorganization of the dead's world of the Tupi-Guarani Indians, in order to fit it in the christian model of afterlife. In consequence, images and visions related to Heaven, Hell and Purgatory were disseminated and translated in multiple forms by the Indians of Portuguese America during the cathechization's process.

KEYWORDS: Brazilian Indians; Jesuits; Catechesis; History of Brazil.

A tentativa de conhecer o passado é também uma viagem ao mundo dos mortos (GINZBURG, 1991, p. 37).

Comprometidos com a conversão dos índios na América portuguesa, sobretudo dos Tupi-Guarani ${ }^{2}$, os jesuítas procuraram reorganizar o mundo dos mortos indígenas, de modo a enquadrá-lo no paradigma cristão do além.

\footnotetext{
${ }^{1}$ Glória Kok é pós-doutora em Antropologia na Unicamp, pesquisadora do Centro de Pesquisa em Etnologia Indígena (CPEI) e autora do Os vivos e os mortos na América portuguesa (Fapesp/Unicamp, 2001) e O sertão itinerante (Fapesp/Hucitec, 2004), entre outras publicações.

${ }^{2}$ Os Tupi viviam no litoral do Amazonas até Cananéia e na região da bacia amazônica, enquanto os Guarani distribuíam-se pela costa de Cananéia ao Rio Grande do Sul, infiltrando-se nas margens dos rios Paraná, Uruguai e Paraguai (CLASTRES, 1978, p. 8).
}

Espaço Ameríndio, Porto Alegre, v. 2, n. 1, p. 8-14, jan./jun. 2008. 
GLÓRIA KOK - Os ameríndios nas redes do sobrenatural cristão.

No universo tupi-guarani, passado, presente e futuro voltavam-se inteiramente para o mundo coletivo dos antepassados, os quais inspiravam regras e normas sociais, encarnando a memória e a identidade das tribos. O post mortem indígena, segundo a crença tupiguarani, situava-se em algum lugar da terra, a conhecida e almejada Terra sem Mal, onde antepassados e deuses partilhavam, num coletivo indiviso, a verdadeira felicidade, sem dor, morte ou miséria. ${ }^{3}$

Já no modelo cristão, os mortos estavam organizados individualmente numa topografia verticalizada e compartimentalizada. Até meados do século XVII, a catequese seguiu o modelo binário de além. Santo Agostinho, um dos maiores defensores da bipartição do mundo dos mortos afirma: "Que não haja mais engano, existem apenas dois lugares" (VOVELLE, 1983, p. 58).

Para efeito didático da conversão, os jesuítas colocaram os índios na mesma encruzilhada em que se via o homem medieval: o céu para os batizados e o inferno para os pagãos. O padre Gaspar Lourenço descortinou, diante do índio que havia se recusado a receber o batismo, "a glória do paraíso e as penas do inferno, e que mui breve ou ele se fazia filho de Deus e herdeiro da glória, ou servo perpétuo do Diabo e morador do inferno" (NAVARRO, 1988, p. 328).

As visões dos índios na ocasião da chegada dos missionários traduziam o desejo de alcançar o paraíso, o que vinha ao encontro da promessa lançada pelos jesuítas e à Terra sem Mal. Um deles, que supostamente havia sentido os efeitos imediatos do batismo, disse que "estivera com Deus no Paraíso" (NÓBREGA, 1988, p.95). Contou Vicente Rodrigues que outro índio "se achava na Glória, cantando pela sua arte, e dizia muitas coisas que lá vira de nossa fé" (NAVARRO, 1988, p. 143).

Entre os Tupinambá do Maranhão, o capuchinho Claude d Abeville disse ter encontrado um índio acometido de uma grande diarréia que "por muitas noites pareceu lhe ver o Céu aberto, e os Caraíbas, Padres ou Profetas (assim chamam eles os Religiosos) lá entrando, e uma voz dizer-lhe: - Se queres salvar-te, é necessário que te laves com á água com que foste aspergido" (ABEVILLE, 1975, p. 292).

\footnotetext{
${ }^{3}$ Para uma discussão detalhada da Terra sem Mal, ver o primoroso trabalho de Hélène Clastres, "Terra sem mal- O profetismo tupi-guarani” (1978).
} 
GLÓRIA KOK - Os ameríndios nas redes do sobrenatural cristão.

Na carta de Antonio Blasquez, o diálogo entre um padre e um índio moribundo referia-se ao céu, como um lugar exclusivo dos cristãos, e ao batismo, como a única via possível de alcançá-lo.

Disse o índio: - Baptisa-me que conheço que não tenho de durar muito.

Padre: - Para que te tenho de baptisar?

Índio enfermo: - Para ir para o céu.

Padre: - Como? Não poderás ir para o céu se não fores batisado.

Índio enfermo: - Para lá não vão sinão os que forem christãos (NAVARRO, 1988, p. 329)

O modelo bipartido do mundo dos mortos também foi adotado na conversão de outros ameríndios. Na Nicarágua, por exemplo, as respostas de um índio a um interrogatório conduzido pelo frei Francisco Bobadilha, em 1538, sugerem uma padronização simplificada do além cristão.

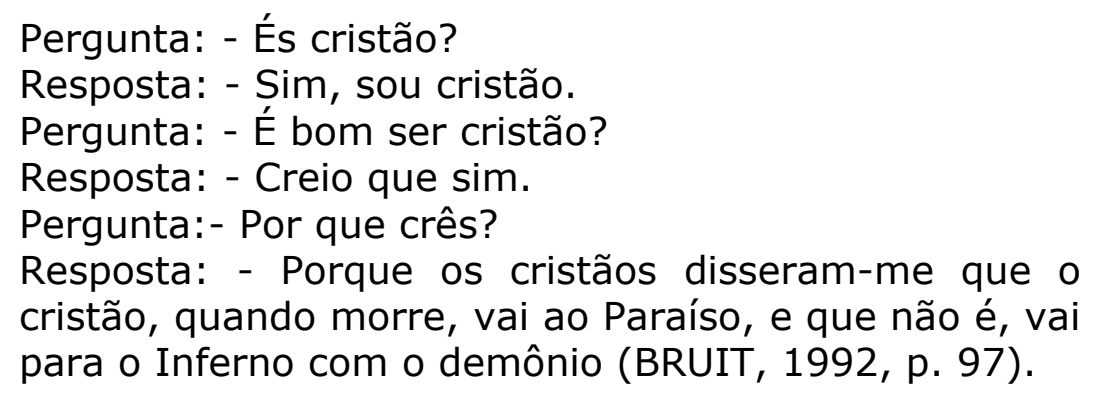

Observa-se, portanto, que a fórmula céu-inferno foi rapidamente digerida pelos índios, mas a resistência ao modelo cristão era, muitas vezes, punida com a morte. O cacique Hatuey recusou o batismo e perguntou se os cristãos iam para o céu. Diante da resposta afirmativa de um padre, o cacique afirmou que não queria ir para lá, "pois eles para lá iam e estavam". Como resultado, "puseram imediatamente fogo à lenha e o queimaram" (SUESS, 1992, p. 83).

No entanto, à medida que avançava o processo de catequização na América portuguesa e aflorava a resistência indígena, o céu cristão tornava-se cada vez mais inacessível aos índios adultos e as notícias do inferno, mais freqüentes. A imagem do paraíso é evanescente, enquanto a do inferno é mais passível de ser visualizada por significar a potencialização dos sofrimentos humanos (VOVELLE, 1983, p. 306). 
GLÓRIA KOK - Os ameríndios nas redes do sobrenatural cristão.

Ora, os surtos epidêmicos de varíola que se alastraram nos aldeamentos no século XVI, do litoral de Pernambuco a São Vicente, adentrando pelo interior, além de terem ocasionado um maciço declínio da população indígena, difundiram uma outra imagem de morte: a morte visível, cujos efeitos eram sentidos na gradual decomposição do corpo. Anchieta deu o seu testemunho do cenário funesto que se descortinava aos índios de São Vicente:

[...] cobre-se todo o corpo dos pés à cabeça de uma lepra mortal que parece couro de cação e ocupa logo a garganta por dentro e a língua de maneira que com muita dificuldade se podem confessar e em três, quatro dias morrem; outros vivem, mas fendendo-se todos e quebra-se-Ihes a carne pedaço a pedaço com tanta podridão de matéria, que sai deles um terrível fedor, de maneira que acodem-Ihe às moscas como à carne morta e apodrecida sobre eles e lhe põem gusanos que se não thes socorressem, vivos os comeriam (ANCHIETA, 1988, p. 248).

Esboçava-se aí a própria imagem do inferno cristão que os índios vivenciaram. Aliás, o cenário de consumição dos corpos em Anchieta tem muito em comum com o cenário descrito na $A$ divina comédia, por Dante Alighieri, quando avista as almas dos falsários: a lepra cobrindo os corpos, a metáfora do peixe e a putrefação dos corpos vivos. Eis o trecho:

Abatida aos montões, aquela gente jazia, num difícil tumultuar, procurando arrastar-se, inutilmente. Os condenados esfregavam as costas: e largas crostas iam arrancando, tal o peixe se vê sob o facão do pescador, que o raspa, descamando (ALIGHIERI, 1999, p. 354).

O terror e o medo infundidos pelas doenças deixavam os índios à mercê da ação dos jesuítas. Afinal, a varíola era a prova viva do apodrecimento do corpo, tão temido pelos Tupi-Guarani. O tratamento dispensado pelos missionários aos índios enfermos consistia em fazer sangrias e esfolar as partes molestas dos corpos com uma tesoura, 
GLÓRIA KOK - Os ameríndios nas redes do sobrenatural cristão.

"ficando em carne viva, [...] e lavando-Ihes aquela corrupção em água quente" (ANCHIETA, 1988, p. 249).

Além dos surtos epidêmicos que desenhavam imagens infernais do sobrenatural cristão, relatos de mortos são recorrentes nos escritos jesuíticos, contribuindo para popularizar e enriquecer as imagens do além. Isabel, índia guarani falecida na missão de Loreto, voltou à vida para narrar sua viagem. Disse que foi levada ao Inferno, onde viu fogo horrendo e nele conseguiu perceber alguns conhecidos que padeciam de muitos tormentos. Em seguida, foi conduzida ao Céu, onde estava "nuestra Madre, tan hermosa, tan resplandecente y linda, tan adorada", [...] na companhia de "Santos hermosíssimos y resplandecientes" e todos Ihes deram os parabéns por fazer parte desta comunidade. Voltava à terra para dizer aos que aqui viviam que "seais verdadeiros Christianos". Voltou a morrer e, depois de oito ou nove meses, desenterraram-na com "las carnes enteras, flegíbles, y sin ningun mal olor" (MONTOYA, 1639, p. 56-57). Apesar de registrar imagens do além cristão, o relato de Isabel denuncia um traço marcante da cultura tupi-guarani: o desejo de reencontrar os antepassados, ao procurar identificar pessoas conhecidas ou do círculo afetivo no mundo dos mortos.

A partir do século XVII, o purgatório, oficializado pelo Segundo Concílio de Lyon, em 1274, começou a ser incorporado pelo imaginário indígena na América portuguesa. Este lugar intermediário entre o céu e o inferno criou um sistema complexo em que os vivos podiam interferir no destino dos mortos, por meio dos sufrágios: rezas, missas e esmolas. Além disso, o purgatório legitimou uma nova aparição dos mortos na terra (LE GOFF, 1981, p. 18). Um jovem índio, cheio de dúvidas em relação às penas do purgatório, entreviu, quando estava para adormecer, pessoas vestidas de branco que lhe ensinaram o que são as penas do purgatório, depois de jogá-lo no fogo (MONTOYA, 1639, p. 60).

Mas a tolerância dos missionários em relação às visões e aos sonhos dos índios desapareceu completamente no século XVIII, sob suspeita de se constituírem manifestações heréticas. Nessa etapa, concepções indígenas conviviam com concepções cristãs na América portuguesa. O índio capitão Marçal Agostinho, segundo depoimento, "forma vozes mudadas, e desconhecidas para que os miseráveis 
GLÓRIA KOK - Os ameríndios nas redes do sobrenatural cristão.

entendam que são pronunciadas por almas do Outro Mundo" (LAPA, 1978, p. 226). O mameluco de nome Pedro Rodrigues, reputado feiticeiro, adivinhador e oráculo, tentou persuadir as índias a cometer infanticídio, assegurando-lhes de que não era "pecado", porque "as almas das mesmas crianças assim mortas nos ventres maternos vem depois falar de outro mundo a ele Pedro Rodrigues" (ANCHIETA, 1988, p. 159).

Concluindo, no processo de catequização, a Companhia de Jesus atuou no sentido de implantar um novo modelo de além, que abrangia do centro da terra aos espaços celestes, o qual, ao reorganizar os mortos numa outra topografia, alterou o circuito dos vivos com os mortos e vice-versa. Os índios mostravam-se vulneráveis, sobretudo no limiar da morte, à absorção de um outro conjunto simbólico. No entanto, para o desespero dos jesuítas, isso não significava necessariamente conversão ao catolicismo. Diversos atores indígenas traduziram e vislumbraram imagens do céu, inferno e purgatório, que, longe de estarem adequadas ao modelo cristão, configuraram-se como fragmentos dispersos e desviantes, numa dinâmica capaz tanto de "suportar conteúdos tradicionais variados" (VIVEIROS DE CASTRO, 2002, p. 209) quanto de absorver acervos simbólicos inéditos. Nesse campo de disputas simbólicas, os Tupi-Guarani conferiram sentidos originais às crenças que envolveram a esfera do sobrenatural na América portuguesa.

\section{Referências bibliográficas:}

ABEVILLE, Claude. História da missão dos padres capuchinhos na ilha de Maranhão. Tradução de Sérgio Milliet. Belo Horizonte/São Paulo: Itatiaia/Edusp, 1975.

ALIGHIERI, Dante. A divina comédia. Tradução de Cristiano Martins. Belo Horizonte: Itatiaia, 1999. 2v.

ANCHIETA, Pe. J. Cartas: informações, fragmentos históricos e sermões. Belo Horizonte/São Paulo: Itatiaia/Edusp, 1988. 
GLÓRIA KOK - Os ameríndios nas redes do sobrenatural cristão.

BRUIT, Héctor. O visível e o invisível na conquista hispânica da América. In: VAINFAS, Ronaldo (Org.). América em tempo de conquista. Rio de Janeiro: Jorge Zahar, 1992. p. 77-101.

CLASTRES, Hélène. Terra sem Mal: o profetismo tupi-guarani. Tradução de Renato Janine Ribeiro. São Paulo: Brasiliense, 1978.

GINZBURG, Carlo. História noturna: decifrando o sabá. Tradução de Nilson Moulin Louzada. São Paulo: Companhia das Letras, 1991.

GAMBINI, Roberto. O espelho índio: os jesuítas e a destruição da alma indígena. Rio de Janeiro: Espaço e Tempo, 1989.

KOK, Glória. Os vivos e os mortos na América portuguesa: da antropofagia à água do batismo. Campinas/SP: Editora da Unicamp/FAPESP, 2001.

LE GOFF, Jacques. La naissance du purgatoire. Paris: Éditions Gallimard, 1981.

LAPA, Rose Roberto Amaral (apresentação). Livro da Visitação do Santo Ofício da Inquisição ao estado do Grão-Pará (1763-1769). Petrópolis: Vozes, 1978.

MONTOYA, Ruiz de. Conquista espiritual hecha por los religiosos de la Compañia de Jesus en las Províncias del Paraguay, Paraná, Uruguay y Tape. Madrid, 1639.

NAVARRO, A. et al. Cartas avulsas: 1560-1568. Belo Horizonte/São Paulo: Itatiaia/Edusp, 1988.

NÓBREGA, Pe. Manoel da. Cartas do Brasil. Belo Horizonte/São Paulo: Itatiaia/Edusp, 1988.

SUESS, Paul (Org.). A conquista espiritual da América espanhola. Petrópolis: Vozes, 1992.

VIVEIROS DE CASTRO, Eduardo. A inconstância da alma selvagem e outros ensaios de antropologia. São Paulo: Cosac \& Naify, 2002.

VOVELLE, M. La morte t l'Occident de 1300 à nos jours. Paris: Gallimard, 1983.

Espaço Ameríndio, Porto Alegre, v. 2, n. 1, p. 8-14, jan./jun. 2008. 